\title{
Myoinositol In Restoring Spontaneous Ovarian Activity in Patients with Polycystic Ovarian Syndrome (PCOS)
}

\section{Ikram-u-Allah, ${ }^{1}$ Nadia Sabeen, ${ }^{2}$ Qaiser Javed Iqbal, ${ }^{3}$ Shazia Zulfiqar, ${ }^{4}$ Tayyiba Wasim ${ }^{5}$}

\begin{abstract}
Objective: To assess the efficacy of myoinositol in the management of patients with Polycystic ovarian syndrome (PCOS)

Methods: It was quasi experimental study conducted inDepartment of Obstetrics and Gynecology Services institute of Medical Sciences, Services Hospital, Lahore from 30-6-2018 to 31-12-2018. 140 sub fertile patients with PCOS were selected through random sampling. Patients were given 2 gram of myoinositol/day. The effect was assessed after 3 and 6 months of treatment by monthly menstrual cycle regularity and ovulation. All this information was recorded in proforma.

Results: The mean age of patients was $26.90 \pm 5.52$ years. The mean BMI of patients was $37.38 \pm 4.08 \mathrm{~kg} / \mathrm{m} 2$. After 3 months of treatment, menstrual cycle become regular in $34(24.3 \%)$ patients and ovulation occurred in $54(38.6 \%)$ cases. After 6 months of treatment, menstrual cycle become regular in $75(53.6 \%)$ patients and ovulation occurred in $101(72.1 \%)$ cases.

Conclusion: The myoinositol is an effective treatment in terms of regularity of menstrual cycle and ovulation induction in subfertile women with PCOS.

Keywords: Myoinositol, Polycystic ovarian syndrome, Menstrual irregularity, Ovulation
\end{abstract}

\section{Introduction}

$\mathrm{P}$ olycystic ovarian syndrome (PCOS) is a multifactorial disorder. The worldwide incidence of polycystic ovarian syndrome (PCOS) is $5-10 \%$ of women of reproductive age. ${ }^{1}$

The clinical feature of PCOS varies from oligomonorrhea, signs of hyperadrogenism such as acne, hirsutism, alopecia, infertility and seborrhea, along with sonographic picture of polycystic ovaries. ${ }^{2}$ It is associated with long term metabolic abnormalities such as obesity, insulin resistance, acanthosisnigricans, type II diabetes mellitus, hypertension and dyslipidemia. ${ }^{3}$ Almost $50-70 \%$ of patients have

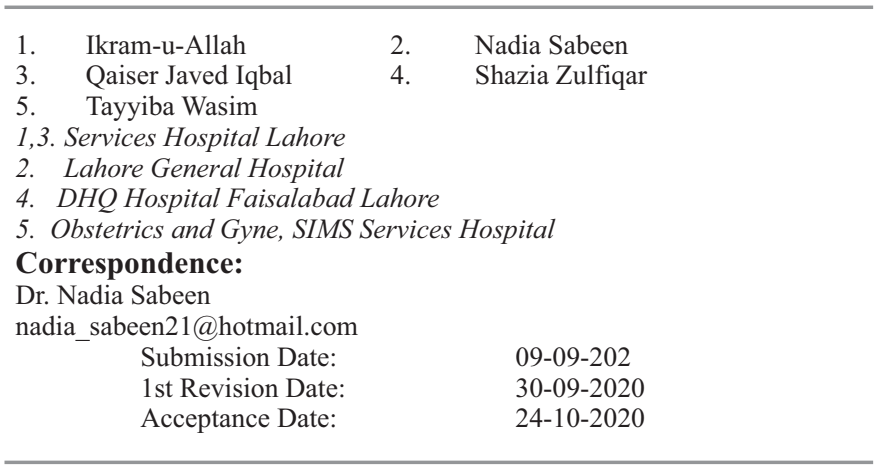

insulin resistance and hyperinsulinemia. ${ }^{4}$ As a result of insulin resistance, hyperinsulinemia alters the FSH to LH shift, insulin increase the production of androgens from the ovary by stimulating cytochrome $\mathrm{P} 450 \mathrm{c} 17 \mathrm{alph}$, and this increased production of androgens leads to anovulatory infertility. There is increase production of testosterone because ovarian theca cells in PCOS affected women are more capable to convert androgens precursors to testosterone. ${ }^{5}$ The insulin sensitizing agent can solve the hyperinsulinemia induced dysfunction of ovarian response to endogenous gonadotrophins, leading to reestablishment of menstrual cyclist, ovulation and increasing pregnancy rates.

Inositol is a chemical compound and nutrient discovered in 1936 and is commonly found in such foods as legumes, meat, citrus fruit, and whole grains in the most common form of Myo-inositol. Myoinositol (a part of vitamin B complex) has a role in both nuclear and cytoplasmic oocyte development, so higher myoinositol level in follicular fluid is an indicator of good oocyte quality. ${ }^{6}$ Inositol phosphate can has a role in activating enzymes that control glucose metabo- 
lism. The altered metabolism of inositol phosphate can mediators in PCOS women contribute to insulin resistance. Insulin sensitizing agent such as Myoinositol reduces production of androgens from theca cells and also reducing testosterone concentration ${ }^{7}$. Myo-inositol is one stereoisomer of a C6 sugar alcohol that belongs to the inositol family. It is the precursor of inositol triphosphate, acting as an intracellular second messenger and regulating a number of hormones such as thyroid-stimulating hormone, FSH and insulin. ${ }^{8}$

Systematic review of randomized trials have shown its efficacy in improving insulin sensitivity of target tissues, restores ovulation and hormonal functions, reduces clinical and biochemical hyperandrogenism and dyslipidemia through reduction of plasma insulin level with success in achieving pregnancy.,

The rationale of my study is to observe the effect of myoinositol in improving metabolic, hormonal and clinical features in patients with PCOS. Although literature is available in studies conducted in other population but there is no local study available in this topic in Pakistan and there are genetic differences from one population to another so the effect of my drug may also vary accordingly and the study results may not be consistent with already existent literature. It may help in improvement of clinical features such as acne, hirsutism and obesity in patients with PCOS, also help in increasing conception rate by restoring spontaneous ovarian activity.

\section{Operational Definitions}

Polycystic ovarian syndrome: in 2003, the European society of human reproduction and Embyology (ESHRE) and American society of reproductive medicine (ASRM) recommends at least 2 of the 3 following features are to be present to diagnose PCOS

1. oligo-ovulation or anovulation manifested my oligomonorrhea or amonorrhea for 6-9 cycles/yr

2. Hyperandrogenism assessed clinically by acne, obesity, hirsutism or hyperandrogenemia assessed biochemically by raised level of testosterone i.e.; $>70 \mathrm{ng} / \mathrm{dl}$.

3. Polycystic ovaries (peripheral arrangement of $>8$ follicles of size $<10 \mathrm{~mm}$ in one or both ovaries) assessed by ultrasound.

\section{Efficacy}

It was assessed on 3rd and 6th months post treatment in terms of:

Restoration of normal menstrual cycle: Normal menstrual cycle ranges from 3-7/21-35 days for 3-6 months assessed by history of the patient

Ovulation: It was the event of de-Graaf's follicle rupturing and releasing secondary oocytes. The normal ovulation day in mostly 14th day of 28 day menstrual cycle. Ovulation was assessed by day 21 progesterone level ranging from 16-28nmol/1.

\section{Methods}

It was quasi experimental study conducted in Department of Obstetrics and Gynecology Services institute of Medical Sciences, Services Hospital, Lahorefrom 30-6-2018 to 31-12-2018. After getting permission from IRB, 140 sub fertile patients with PCOS were selected through Non- probability consecutive sampling. Inclusion criteria was 18 to 35 years of age, married women.

Sub-fertile women assessed by history i.e. not able to conceive after at least one year of regular, unprotected sex.

Patients selected with PCOS according to Rotterdam criteria as per operational definition. Patients known allergic myoinositol and non-complaint patients were excluded. A detailed history was taken regarding menstrual cycle, infertility, weight gain, acne, hirsutism, clinical examination including weight, height, blood pressure were noted and investigation such as transvaginal ultrasound was performed assessment of ovulation was done by measuring day 21 progesterone level ranges from 16 to $28 \mathrm{nmol} / 1$.

Patients were given 2 gram of myoinositol/day. The effect was assessed after 3 and 6 months of treatment by monthly menstrual cycle regularity and ovulation. All this information was recorded in proforma.

\section{Data Analysis}

SPSS version 21.0 was used for data analysis. Quantitate variables like patient's age, hormonal profile were presented by mean and standard deviation. Qualitative variables like ovulation, mens- 
trual cycle regularity were presented by calculating frequency and percentages. Data was stratified for age, duration of PCOS and BMI. Post-stratification, chi-square test was used taking P-value $\leq 0.05$ as significant.

\section{Results}

The mean age of patients was $26.90 \pm 5.52$ years. The mean BMI of patients was $37.38 \pm 4.08 \mathrm{~kg} / \mathrm{m} 2$. Table 1

After 3 months of treatment, menstrual cycle become regular in $34(24.3 \%)$ patients while irregular in 106 $(75.7 \%)$ patients and ovulation occurred in 54 (38.6\%) cases while did not occurred in 86 (61.4\%) cases. After 6 months of treatment, menstrual cycle become regular in 75 (53.6\%) patients and ovulation occurred in $101(72.1 \%)$ cases. Table 2

Table 1: Descriptive Statistics of Patients

\begin{tabular}{cc}
\hline Age (years) & $\mathbf{1 4 0}$ \\
\cline { 2 - 2 } BMI & $26.90 \pm 5.52$ \\
\hline
\end{tabular}

Data was stratified for age of patients. After 3 months, in patients aged 18-25years, menstrual cycle become regular in $16(26.2 \%)$ cases and ovulation occurred in $20(32.8 \%)$. After 3 months, in patients aged 26-35 years, menstrual cycle become regular in $18(22.8 \%)$ cases and ovulation occurred in 34 (43.0\%). The difference was insignificant in both age strata Table 2: Distribution of outcome at 6th Month

\begin{tabular}{cccc}
\hline & & Frequency & Percent \\
\hline \multirow{2}{*}{ Menstrual cycle } & Regular & 75 & 53.6 \\
& Irregular & 65 & 46.4 \\
\multirow{2}{*}{ Ovulation } & Yes & 101 & 72.1 \\
& No & 39 & 27.9 \\
\hline
\end{tabular}

$(\mathrm{p}>0.05)$.

Data was stratified for age of patients. After 6 months, in patients aged 18-25years, menstrual cycle become regular in $34(55.7 \%)$ cases and ovulation occurred in $44(72.1 \%)$. After 6 months, in patients aged 26$35 y e a r s$, menstrual cycle become regular in 41 $(51.9 \%)$ cases and ovulation occurred in 57 (72.2\%). The difference was insignificant in both age strata $(\mathrm{p}>0.05)$. Table 3

Data was stratified for BMI of patients. After 3 months, in normal BMI patients, menstrual cycle become regular in $15(32.6 \%)$ cases and ovulation occurred in $19(41.3 \%)$. After 3 months, in overweight patients, menstrual cycle become regular in $17(33.3 \%)$ cases and ovulation occurred in 27

Table 3: Comparison of Outcome in Age Strata at 6th Month

\begin{tabular}{|c|c|c|c|c|c|}
\hline & & \multicolumn{2}{|c|}{ Age (years) } & \multirow[t]{2}{*}{ Total } & \multirow{2}{*}{$\begin{array}{c}\text { P- } \\
\text { value }\end{array}$} \\
\hline & & $18-25$ & $26-35$ & & \\
\hline \multirow{4}{*}{$\begin{array}{l}\text { Menstrual } \\
\text { cycle }\end{array}$} & \multirow[t]{2}{*}{ Regular } & 34 & 41 & 75 & \multirow[t]{4}{*}{0.652} \\
\hline & & $55.7 \%$ & $51.9 \%$ & $53.6 \%$ & \\
\hline & \multirow[t]{2}{*}{ Irregular } & 27 & 38 & 65 & \\
\hline & & $44.3 \%$ & $48.1 \%$ & $46.4 \%$ & \\
\hline \multirow{4}{*}{ Ovulation } & \multirow[t]{2}{*}{ Yes } & 44 & 57 & 101 & \multirow[t]{4}{*}{0.998} \\
\hline & & $72.1 \%$ & $72.2 \%$ & $72.1 \%$ & \\
\hline & \multirow[t]{2}{*}{ No } & 17 & 22 & 39 & \\
\hline & & $27.9 \%$ & $27.8 \%$ & $27.9 \%$ & \\
\hline
\end{tabular}

(52.9\%).After 3 months, in obese patients, menstrual cycle become regular in $2(4.7 \%)$ cases and ovulation occurred in $8(18.6 \%)$. The difference was significant in all BMI strata $(\mathrm{p}<0.05)$. Table 4

Data was stratified for BMI of patients. After 6 months, in normal BMI patients, menstrual cycle become regular in $33(71.7 \%)$ cases and ovulation occurred in $38(82.6 \%)$. After 6 months, in overweight patients, menstrual cycle become regular in 25

Table 4: Comparison of Outcome in BMI Strata at 3rd Month

\begin{tabular}{|c|c|c|c|c|c|c|}
\hline & & \multicolumn{3}{|c|}{ BMI } & \multirow[b]{2}{*}{ Total } & \multirow{2}{*}{$\begin{array}{c}\text { P- } \\
\text { value }\end{array}$} \\
\hline & & Normal & $\begin{array}{c}\text { Over- } \\
\text { weight }\end{array}$ & Obese & & \\
\hline \multirow{4}{*}{$\begin{array}{l}\text { Menstrual } \\
\text { cycle }\end{array}$} & Regular & 15 & 17 & 2 & 34 & \multirow{4}{*}{0.001} \\
\hline & \multirow{3}{*}{ Irregular } & $32.6 \%$ & $33.3 \%$ & $4.7 \%$ & $24.3 \%$ & \\
\hline & & 31 & 34 & 41 & 106 & \\
\hline & & $67.4 \%$ & $66.7 \%$ & $95.3 \%$ & $75.7 \%$ & \\
\hline \multirow{4}{*}{ Ovulation } & Yes & 19 & 27 & 8 & 54 & \multirow{4}{*}{0.003} \\
\hline & & $41.3 \%$ & $52.9 \%$ & $18.6 \%$ & $38.6 \%$ & \\
\hline & No & 27 & 24 & 35 & 86 & \\
\hline & & $58.7 \%$ & $47.1 \%$ & $81.4 \%$ & $61.4 \%$ & \\
\hline
\end{tabular}

(49.0\%) cases and ovulation occurred in 37 (72.5\%). After 6 months, in obese patients, menstrual cycle become regular in $17(39.5 \%)$ cases and ovulation occurred in $26(60.5 \%)$. The difference was significant in all BMI strata $(\mathrm{p}<0.05)$ for menstrual regularity while insignificant for ovulation $(\mathrm{p}>0.05)$. Table 5

\section{Discussion}

PCOS is a metabolic disorder that is associated with wide range of hormonal and biochemical dysfunc- 
tion. It has a high prevalence among Pakistani women

Table 5: Comparison of Outcome in BMI Strata at 6th Month

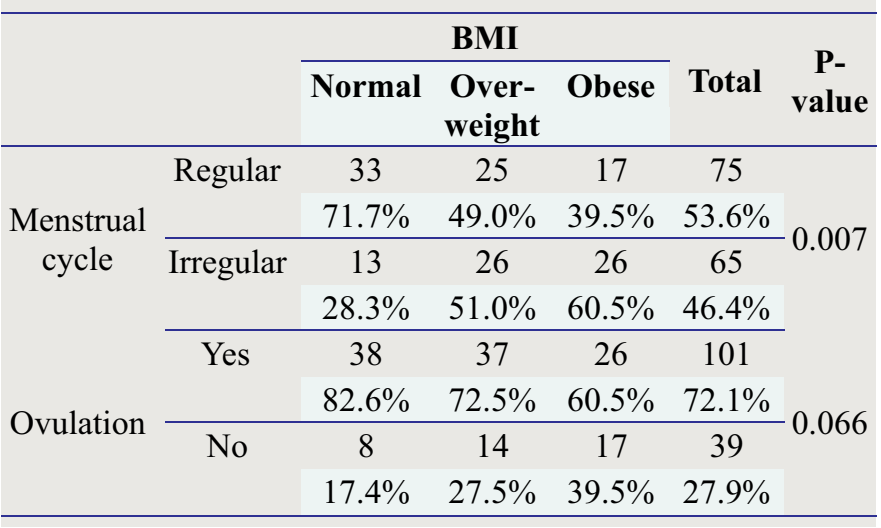

$(52 \%)$ as compared to Caucasians $(20-25 \%)^{11}$. The main reason for associated infertility is that the eggs in the ovaries are unable to mature efficiently and cannot be released, resulting in small cyst formations and ovarian inflammation. In fact, the presence of PCOS puts an individual at a significantly higher risk of developing type II diabetes, hypertension, gynecologic carcinomas, certain psychological conditions and low quality of life. ${ }^{12}$

In our study, the mean age of patients was $26.90 \pm 5.52$ years. Data was stratified for age of patients. After 6 months, in patients aged 18-25years, menstrual cycle become regular in $34(55.7 \%)$ cases and ovulation occurred in 44 (72.1\%). In patients aged 26-35years, menstrual cycle become regular in $41(51.9 \%)$ cases and ovulation occurred in $57(72.2 \%)$. The difference was insignificant in both age strata $(p>0.05)$. The patients with subfertility belong to reproductive age group. Myoinositol was effective in older age group as well. Myoinositol has shown to improve metabolic dysfunction in postmenopausal women as well. ${ }^{13}$

In our study, myoinositol was found effective in inducing menstrual cycle regularity in in $75(53.6 \%)$ patients and ovulation occurred in $101(72.1 \%)$ cases after 6 months of treatment. Similar results have been shown in other studies where $61.7 \%$ to $65.5 \%$ female had ovulation. ${ }^{8,1415}$ It is a very important finding for subfertile women with PCOS. Subfertility is a curse for women of Sub continent. They are subject to all sorts of emotional harassment and stigmatized but also face threats of divorce and physical violence. ${ }^{16}$

Improved pregnancy rates have been reported in various studies as well but we did not follow patients for pregnancy. No moderate to severe side effects were observed when myo-inositol was used at a dosage of $2000 \mathrm{mg}$ per day in our study.

The use of $2000 \mathrm{mg}$ myo-inositol per day is well tolerated by patients in other studies as well. ${ }^{16,17}$ PCOS is also associated with the failure of in vitro fertilization as these patients suffer from poor quality oocytes. Myoinositol has been found to improve quality of oocytes as it improves insulin sensitivity and decrease hyperandogenism. ${ }^{18}$

In our study, the mean BMI of patients was $37.38 \pm$ $4.08 \mathrm{~kg} / \mathrm{m}^{2}$. Increased BMI is itself associated with insulin resistance and decreased chances of fertility. Data was stratified for BMI of patients. After 6 months, in normal BMI patients, menstrual cycle become regular in $33(71.7 \%)$ cases and ovulation occurred in 38 (82.6\%). In overweight patients, menstrual cycle become regular in $25(49.0 \%)$ cases and ovulation occurred in 37(72.5\%). In obese patients, menstrual cycle become regular in 17(39.5 $\%)$ cases and ovulation occurred in $26(60.5 \%)$. The difference was significant in all BMI strata $(\mathrm{p}<0.05)$ for menstrual regularity while insignificant for ovulation $(p>0.05)$. Myoinositol has been found to facilitate weight loss in PCOS patients in addition to improving biochemical and endocrine parameters ${ }^{19,20}$. Inositols have emerged as important component of endocrine modulation especially linked to insulin signalling ${ }^{21}$. More research is needed to generate local data so that national guidelines can be formulated.

\section{Conclusion}

The myoinositol is found to be effective in inducing ovulation and menstrual cycle regularity in sub fertile PCOS patients.

\section{Author's Contribution}

IU: Conceptalized and design the study.

NS:Data Maintenance

QJ, SZ: Data entry, Statistical Analysis

TW: Approved the final version and Data review Data

AK: Data Collection

\section{References}

1. Madnani N, Khan K, Chauhan P, Parmar G. Polycystic ovarian syndrome. Indian Journal of Dermatology, Venereology, and Leprology [Review Article] 2013 May 1, 2013;79(3):310-21. 
2. Galletta M, Grasso S, Vaiarelli A, Roseff SJ. Bye-bye chiro-inositol-myo-inositol: true progress in the treatment of polycystic ovary syndrome and ovula-tion induction. Eur Rev Med Pharmacol Sci 2011; 15(10): 1212-4.

3. Morgante G, Orvieto R, Di Sabatino A, Musacchio MC, De Leo V. The role of inositol supplementation in patients with polycystic ovary syndrome, with insulin resistance, undergoing the low-dose gonadotropin ovulation induction regimen. Fertility and sterility 2011;95(8):2642-4

4. Artini PG, Di Berardino O, Papini F, Genazzani A, Simi G, Ruggiero M, et al. Endocrine and clinical effects of myo-inositol administration in polycystic ovary syndrome. A randomized study. Gynecological Endocrinology 2013;29(4):375-9.

5. Unfer V, Nestler JE, Kamenov ZA, Prapas N, Facchinetti F. Effects of inositol (s) in women with PCOS: a systematic review of randomized controlled trials. International journal of endocrinology 2016; 2016.

6. Costantino D, Minozzi G, Minozzi E, Guaraldi C. Metabolic and hormonal effects of myo-inositol in women with polycystic ovary syndrome: a doubleblind trial. Eur Rev Med Pharmacol Sci 2009; 13(2): 105-10.

7. Ciotta L, Stracquadanio M, Pagano I, Carbonaro A, Palumbo M, Gulino F. Effects of myo-inositol supplementation on oocyte's quality in PCOS patients: a double blind trial. Eur Rev Med Pharmacol Sci 2011;15(5):509-14.

8. Bizzarri M, Fuso A, Dinicola S, Cucina A, Bevilacqua A. Pharmacodynamics and pharmacokinetics of inositol (s) in health and disease. Expert opinion on drug metabolism \& toxicology 2016;12(10):118196.

9. Unfer V, Carlomagno G, Dante G, Facchinetti F. Effects of myo-inositol in women with PCOS: a systematic review of randomized controlled trials. Gynecological Endocrinology 2012. 28 509-515. (10.3109/09513590.2011.650660)

10. Unfer V, Nestler JE, Kamenov ZA, Prapas N, Facchinetti F. Effects of Inositol(s) in Women with PCOS: A Systematic Review of Randomized Controlled Trials. Int J Endocrinol. 2016;2016: 1849162. doi:10.1155/2016/1849162

11 Akram M, Roohi N. Endocrine correlates of polycystic ovary syndrome in Pakistani women. J Coll Physicians Surg Pak. 2015 Jan; 25(1):22-6. PMID: 25604364.

12. Sidra S, Tariq MH, Farrukh MJ, Mohsin M. Evaluation of clinical manifestations, health risks, and quality of life among women with polycystic ovary syndrome. PLoS One [Internet]. 2019 Oct 11; 14(10):e0223329. Available from: https://doi.org/ 10.1371/journal.pone.0223329

13. Giordano D, Corrado F, Santamaria A, Quattrone S, Pintaudi B, Di Benedetto A, D'Anna R. Effects of myo-inositol supplementation in postmenopausal women with metabolic syndrome: a perspective, randomized, placebo-controlled study. Menopause. 2011 Jan;18(1):102-4. doi: 10.1097/ gme. 0b013e3181e8e1b1. PMID: 20811299.

14. Heimark D, McAllister J, Larner J. Decreased myoinositol to chiro-inositol $(\mathrm{M} / \mathrm{C})$ ratios and increased $\mathrm{M} / \mathrm{C}$ epimerase activity in PCOS theca cells demonstrate increased insulin sensitivity compared to controls. Endocrine Journal 2013:EJ13-0423.

15. Kamenov Z, Kolarov G, Gateva A, Carlomagno G, Genazzani AD. Ovulation induction with myoinositol alone and in combination with clomiphene citrate in polycystic ovarian syndrome patients with insulin resistance. Gynecol Endocrinol 2015;31(2): 131-5.

16. Muhammad, D., \& Begum, N. (2019). HEALTH AND SOCIAL ISSUES OF INFERTILE WOMEN IN PAKISTAN. Annals of Allied Health Sciences, 4(2), 31-32

17. Malvasi A, Casciaro F, Minervini M, Kosmas I, Mynbaev O, Pacella E, et al. Myo-inositol, D-chiroinositol, folic acid and manganese in second trimester of pregnancy: a preliminary investigation. Eur Rev Med Pharmacol Sci 2014;18(2):270-4.

18. Regidor PA, Schindler AE, Lesoine B, Druckman R. Management of women with PCOS using myoinositol and folic acid. New clinical data and review of the literature. Hormone molecular biology and clinical investigation 2018 Mar 2;34(2).

19. Saleem F, Rizvi SW. New Therapeutic Approaches in Obesity and Metabolic Syndrome Associated with Polycystic Ovary Syndrome. Cureus. 2017; 9(11): e1844. Published 2017 Nov 13. doi: 10.7759/ cureus. 1844

20. Genazzani AD, Santagni S, Rattighieri E, Chierchia E, Despini G, Marini G, Prati A, Simoncini T. Modulatory role of D-chiro-inositol (DCI) on LH and insulin secretion in obese PCOS patients. Gynecol Endocrinol. 2014 Jun;30(6):438-43. doi: 10.3109/ 09513590.2014.897321. Epub 2014 Mar 7. PMID: 24601829.

21. Muscogiuri G, Palomba S, Laganà AS, Orio F. Inositols in the Treatment of Insulin-Mediated Diseases [published correction appears in Int J Endocrinol. 2016;2016:6189820]. Int J Endocrinol. 2016; 2016: 3058393. doi:10.1155/2016/3058393 